\title{
Intravenous to oral antimicrobial stepdown therapy at the Henderson Hospital, Hamilton, Ontario
}

\author{
LA MANDELL MD, C ROTSTEIN MD, S SALAMA MD
}

I N AN ATTEMPT TO DEAL WITH THE PROBLEM OF INCREASING costs of antimicrobials, a number of cost-saving measures were introduced at the Henderson Hospital in August 1992. The three main measures were:

- restricted drugs

- therapeutic interchange (automatic substitution)

- sequential antibiotic therapy or intravenous to oral switchover.

The average monthly purchasing costs for antimicrobials have decreased from $\$ 119,841$ per month in 1992 to $\$ 108,364$ in 1993 and to $\$ 80,770$ in 1994 . This represents an average monthly savings of $\$ 39,100$ over the two years or $\$ 469,200$ per year. When we examined the cost savings associated with each of the three measures mentioned above, we found that most of the savings were due to the restricted drugs and therapeutic interchange policies. The intravenous to oral switchover was not as successful as we had hoped. When we examined the results with two drugs in particular, metronidazole and cotrimoxazole, the cost reduction per year attributable to these drugs was only $\$ 1,489$ and $\$ 2,546$ respectively.

In an attempt to remedy this situation, we decided to see what the effect of specific interventions would be on the percentage of patients switched from intravenous to oral therapy. We felt that there were essentially three

Division of Infectious Diseases, Department of Medicine, Henderson General Hospital, McMaster University, Hamilton, Ontario

Correspondence: Dr LA Mandell, Division of Infectious Diseases, Department of Medicine, Henderson General Hospital, 711 Concession Street, Hamilton, Ontario L8V IC3, telephone 905-574-8520, Fax 905-575-7320 steps at which interventions could be made and these are described below.

As part of our antimicrobial formulary policy, a number of drugs have been identified which can be given intravenously as well as orally. These include the following: metronidazole, clindamycin, cotrimoxazole, fluconazole, cefuroxime, erythromycin, acyclovir, cloxacillin, ciprofloxacin and cephalexin. Whenever one of these drugs is ordered to be given intravenously, the pharmacy sends up a yellow sticker to remind the physician that the drug may also be given orally. For each of these drugs, the corresponding sticker, or 'sequential therapy reminder' lists pertinent information regarding the price, dose and frequency of administration. The sticker is placed on the patient's chart by the ward nurse, and hopefully the patient's physician will respond to this gentle reminder. We were disappointed to find that in only $27 \%$ of eligible cases was the intravenous to oral switch actually being made.

The three points at which interventions could take place are:

Step 1 - the pharmacy when the stickers are sent up with the intravenous drug

Step 2 - the ward where the stickers are placed on the patient's chart

Step 3 - the physician.

A summer student working at our hospital was assigned this task. Each intervention was carried out for two weeks and the results averaged to provide data for a one week period. When the student intervened at step 1 , she herself sent the yellow stickers to the ward; this increased compliance from $27 \%$ to $40 \%$. For step 2 , she put the stickers onto the chart herself and compliance 
increased to $52 \%$. When physicians did not respond to the yellow sticker, she discussed the program with the individual physician and this increased the response rate to $76 \%$. This translated into a saving of $\$ 1,000$ per week. We feel that the important point to be realized is that good programs are not sufficient. Despite the best intentions of all involved, careful follow-up is critical to the success of any antimicrobial policy. 


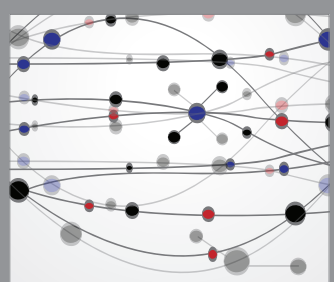

The Scientific World Journal
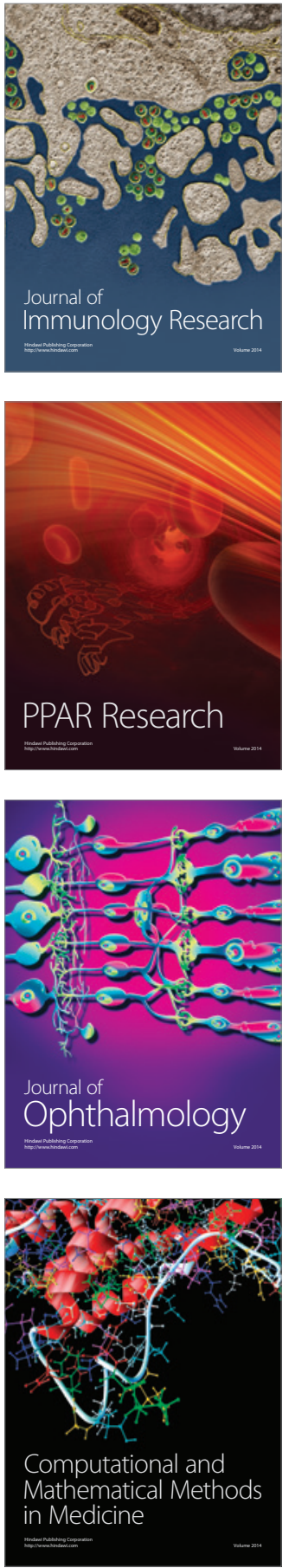

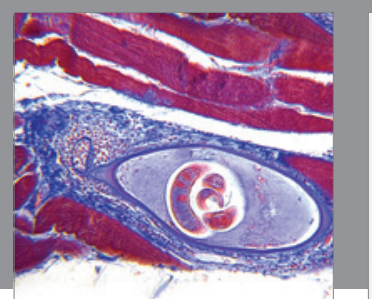

Gastroenterology Research and Practice

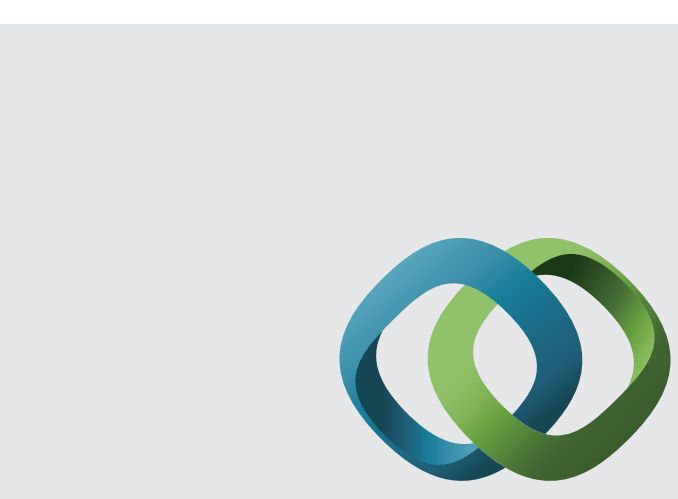

\section{Hindawi}

Submit your manuscripts at

http://www.hindawi.com
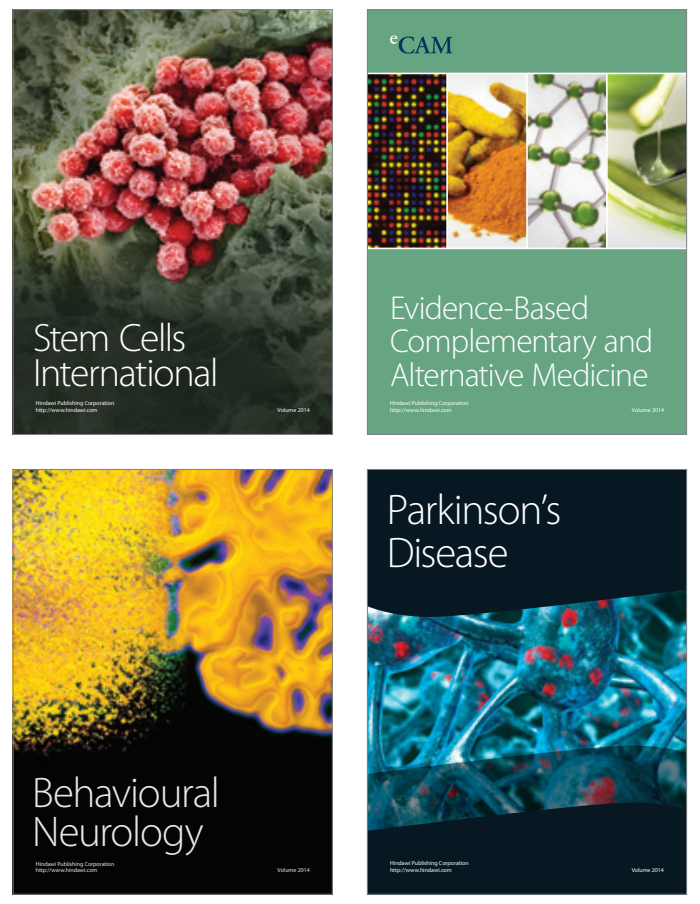
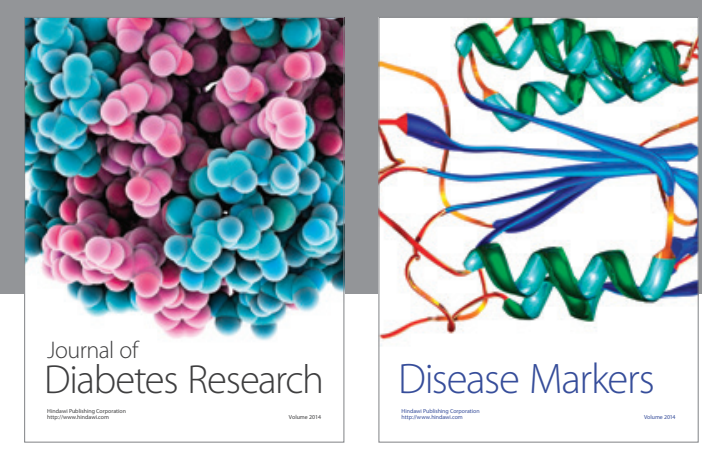

Disease Markers
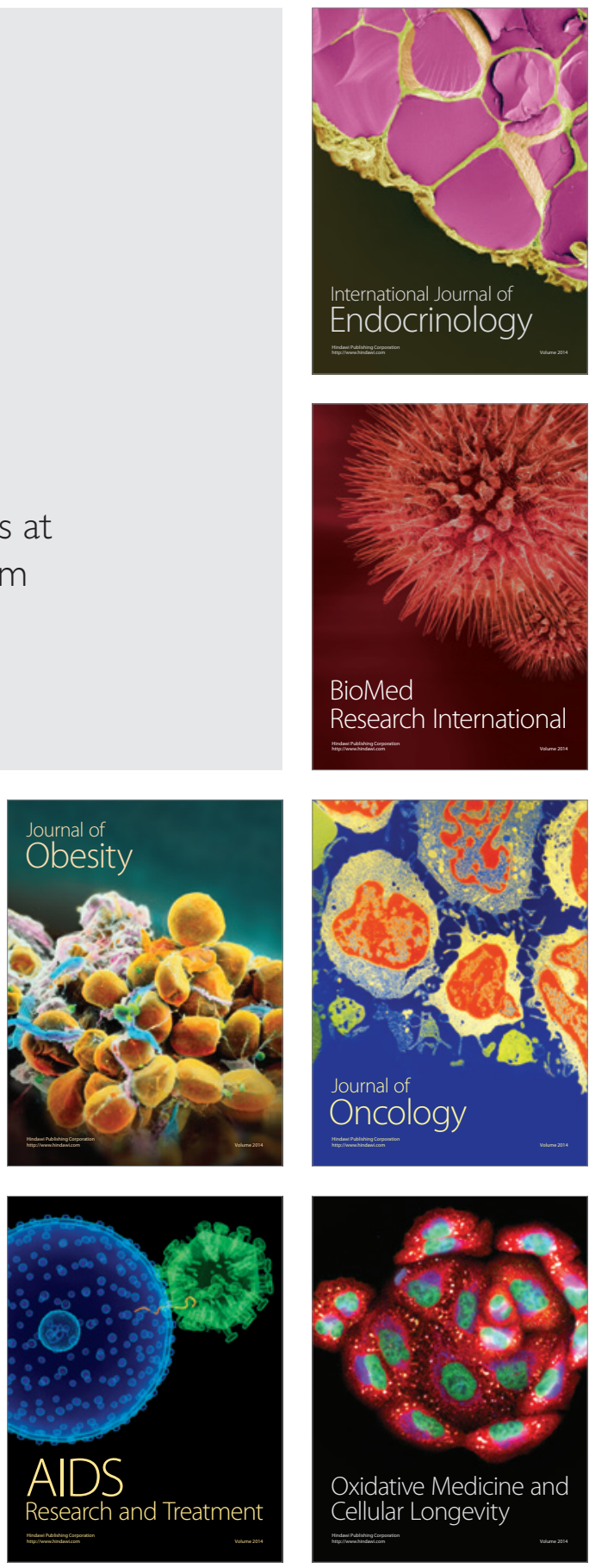